\title{
GPS 技术在工程测量中的应用研究
}

\section{Application of GPS Technology in Engineering Survey \\ 刘建东 潘玉麟 毕新普 \\ Jiandong Liu Yulin Pan Xinpu Bi}

山东志诚地理信息技术有限公司

中国・山东淄博 255000

Shandong Zhicheng Geographic Information

Technology Co.,Ltd.,

Zibo, Shandong, 255000, China

\section{1 引言}

随着近几年的经济发展提高, 对于工程施工的精准度、标 准度都不断提高, GPS 已经成为当前提高工程测量技术的重 要技术内容。GPS 技术在工程测量中的应用主要是通过接收 器接收卫星发生的信号, 然后通过计算机器械进行数据处理, 最后得出相关的空间坐标位置。

\section{GPS 技术的主体}

GPS 技术相比较于传统的工程测量技术,拥有全能型、全 球性、全天候等多种优点, 能应用在多种工程领域的测量。这 里需要介绍一下 GPS 的应用主体, 也就是空间卫星星座、地 面监控站及用户设备三部分。

\section{1 空间卫星星座}

GPS 技术所应用的空间卫星星座是由 21 颗工作卫星、3颗 在轨备用卫星组成。这 24 颗卫星均匀地分布在地球外的 6 个 轨道平面, 确保任何时刻都有至少 3 颗卫星覆盖地面, 达到工 程测量定位目的。

\section{2 地面监控站}

GPS 技术的地面监控站是对 GPS 卫星的观测站点,通过 地面监控站分析 GPS 卫星发来的信息数据, 计算卫星的轨道 参数和钟差参数, 并将计算、编制后的数据导航电文, 传送进 注人站,由注入站传输到相应卫星的存储器中 ${ }^{[1]}$

\subsection{GPS 接收机}

GPS 技术在工程测量应用的时候, 通常都是工程测量人 员手持 GPS 接收机进行测量活动。通过 GPS 接收器捕获卫星 信息, 对信号进行放大、转换和处理, 就能够通过计算机和对 应软件求出并显示当前的三维坐标。

\section{GPS 技术在工程测量中的应用}

\section{1 建筑测绘方面应用}

\section{1 .1 范围广}

GPS 技术之所以能够在各行业迅速应用的重要特点就是 范围广, 在面对一些建筑建设工程的时候, GPS 定位测量技术 能够更方便地进行建筑工程实地测绘。尤其是 GPS 定位测量 技术的实时动态差分法, 在建筑测绘中的应用, 不但可以实时 获取当地的土地界桩具体位置, 还能够确保测数据的精准性, 精度能够达到厘米级别。同时, GPS 技术还能够根据三维坐标 进行电子绘制工程设计图纸, 相比较于传统的电子手动测绘 绘图软件, 大大降低了工作量, 提升了工程测量工作的效率。

\section{1 .2 降低人工成本}

相比较传统测量技术 $3 \sim 5$ 人/次的测绘工作,使用 GPS 技 术之后, 只需要一个人就能够很好地完成原来一个三人小组 才能完成的工程测量工作任务。因此,GPS 技术在建筑工程测 量中的应用, 在提高工程测量精度和工作效率的基础上, 还有

（下转第 22 页） 
勘测信息 Survey Information

表 1 地理国情监测的主要内容

\begin{tabular}{c|c|c}
\hline 类型 & 监测要素 & 监测内容 \\
\hline 地表覆盖分类监测 & $\begin{array}{c}\text { 测地、完林、林地、草 } \\
\text { 地、荒漠、裸露地表、位置、范围、面积、类 } \\
\text { 房屋建筑、道路、构筑 } \\
\text { 物、人工堆掘地 }\end{array}$ & $\begin{array}{c}\text { 型等 } \\
\text { 地理国情要素监测 }\end{array}$ \\
$\begin{array}{c}\text { 道路、水域、构筑物、、类型、长度、面积、空 } \\
\text { 地理单元 }\end{array}$ & 间分布等 \\
\hline
\end{tabular}

要决策。在监测自然地理要素时, 应考虑水文地质环境的影 响,有些植被覆盖面积大的地区可能不易测量, 这是监测工作 的重点。在监考虑到一些工程建设影响人类地理环境时, 监测 人员应该进行测试,且在一些区域环境的变化下,一些工业厂 区的地理区域划分可能不同, 也需要监测人员结合相应的地 理位置进行监测。

\section{6 中国开展地理国情监测工作的必要性}

\section{1 有利于建设信息化和谐社会}

地理国情信息在实际的监测工作中, 是从地理的角度进 行分析、研究和描述国情, 加强对资源、环境和生态条件的调 查、监测、评价和预测。因此,开展地理国情监测工作,还可以 优化各类资源配置, 促进区域优势互补, 最终实现人与自然的
和谐相处。

\section{2 有利于更好地应对突发事件}

地理国情监测可以客观公正地监测和统计分析中国的地 表自然和人文信息变化、国家主体功能区规划的实施情况、国 家和地方重大项目的进展情况。因此, 通过开展地理国情监 测, 可以快速获取地表植被、土地利用、生态变化、环境演变等 各类地理国情信息, 揭示经济社会发展与自然资源环境的内 在联系和演变规律, 为国家和地区制订发展战略和规划、保护 生态环境安全、应对突发事件提供有效的数据资料支持。

\section{7 结语}

综上所述, 地理国情监测工作对于中国的社会发展和经 济进步都有着十分重要的意义。因此,政府和相关部门都应该 加强对地理国情监测的重视, 完善相关的技术体系, 提高地理 测绘水平, 促进中国的整体进步。

\section{参考文献}

[1]李德仁,丁霖,邵振峰.关于地理国情监测若干问题的思考 [J]. 武汉大学学报(信息科学版),2016,41(2):143-147.

[2]王华,洪亮,周志诚,等.地理国情监测的应用分析和对策[J].地 理空间信息,2016,14(1):4-7.

\section{（上接第 20 页）}

效地降低了人工成本。同时, 也深化了 GPS 定位测量技术在 建筑工程中的应用,提高房地产行业的发展速度 ${ }^{\left[{ }^{2]}\right.}$ 。

\section{2 现代化城市建设应用}

3.2.1 提高城市建设的控制力度

现代的城市发展速度越来越快, 在城市的建设过程中, 对 于城市工程测量的精准度要求更高。尤其是在城市设备数量 不断增多、城市现代化工程内容的科学性、技术性也在不断提 高,这也造成了现代化城市建设过程中,城市建设控制网要对 城市的建筑建设提高控制力度。GPS 技术在城市建设的应用, 配合城市电子地图，能够提高城市建设控制网对工程的控制 力度,降低注入挖断缆线这样的破坏事件出现, 为城市的健康 发展带来安全保障。

\section{2 .2 更高的精度标准}

在工程测量中, GPS 技术以高精度、广范围为优点获得广 泛使用。但是 GPS 技术最适合应用的区域是空间比较空旷、 广阔的区域,城市高楼林立, 对 GPS 技术的应用存在一定的 阻碍。加上城市建设和普通的建筑建设工程相比较, 城市的施 工环境更加复杂、标准更为严苛, 工程的时间也更短, 通过增 强信号转换的方式，对城市控制测量的 GPS 测量速率、准确性
进行改善。不过随着 GPS 技术在城市建设中的应用, 也大大提 高了城市的建设测量水平, 促进了现代化城市的建设进程。

\section{4 水下工程测绘应用}

水下工程是近几年新兴发展的工程建设项目, 其中包括 但不限于码头、港口、航道整治等。水下工程的应用尤其是以 海洋资源的开发利用为重点, 这些都需要精度非常高的地形 测绘图, 而且工程测量的难度相比于城市建设测量、建筑工程 测量影响的因素更多,比如, 水下暗流的影响是当前一直在攻 克的难题。

\section{5 结语}

GPS 技术在工程测量中的应用只是刚刚起步, 关于 GPS 的相关技术发展的运用标准还没有完善的制度规范，尤其是 中国并没有统一的地理信息基准, 让 GPS 技术在工程测量中 的发展充满了局限。

\section{参考文献}

[1]刘友山.GPS 测绘技术在工程测绘中的应用 [J].建材与装饰， 2020(3):229-230.

[2]黄敏.现代测绘技术在工程测量中的应用及完善策略[J].计算 机产品与流通,2019(12): 144. 